\title{
The effect of dispersing agent on the dyeing of polyester fabrics with disperse dyes derived from 1,4-diethyl-2,6-dioxo-1,2,5,6-tetrahydropyridine-3- carbonitrile
}

\author{
Alya Al-Etaibi a,*, Morsy Ahmed El-Apasery ${ }^{b}$, and Nouria Al-Awadic ${ }^{c}$ \\ a Natural Science Department, College of Health Science, Public Authority for Applied Education and Training, Fayha, 72853, Kuwait \\ ${ }^{\mathrm{b}}$ Dyeing, Printing and Textile Auxiliaries Department, Textile Research Division, National Research Centre, 12622, Dokki, Giza, Egypt \\ c Department of Chemistry, Faculty of Science, Kuwait University, Safat, 13060, Kuwait \\ ${ }^{*}$ Corresponding author at: Natural Science Department, College of Health Science, Public Authority for Applied Education and Training, Fayha, 72853, Kuwait. \\ Tel.: +965.99807246; fax: +965.24832657. E-mail address: alva aletaibi@yahoo.com (A. Al-Etaibi).
}

\begin{tabular}{l} 
ARTICLE INFORMATION \\
\hline Received: 20 May 2013 \\
Received in revised form: 04 June 2013 \\
Accepted: 08 June 2013 \\
Online: 30 September 2013 \\
KEYWORDS \\
Disperse dyes \\
Polyester fabrics \\
Fastness properties \\
Dispersing agent \\
Sodium lignin sulfonate \\
X-ray crystal structure determinations \\
\hline
\end{tabular}

\section{Introduction}

Disperse dyes are used in aqueous dyebaths in the form of fine dispersions, because of their very low solubility, even at high dyeing temperatures. During manufacturing dispersing agents are incorporated into the dye powders to confer the dyeing properties required of commercial dyestuffs [1,2]. In dyeing of polyester several parallel processes can be distinguished as dissolution and redissolution of dye, transfer of dissolved dye from the bulk of the liquor to the fibre surface, adsorption of dye at the fibre surface and finally diffusion from the fibre surface into the polymer [3,4]. One important aspect of dyeing with disperse dyes is the state of dye in the dyebath during dyeing, the finely divided dispersion of dye particles acting as a dye reservoir. The solubility of disperse dyes, though minute, is also a very important factor. In addition, the stability of the dye dispersion, the equilibrium between dye dispersion and dye in true solution in the dyebath, and the rate of dyeing are all affected by the type and concentration of the dispersing agents [5]. Pyridinone disperse dye derivatives have found many applications on different fabrics [6-9]. Keeping in mind the biological importance of the above mentioned heterocyclic compounds and in continuation to our endeavour towards environmentally benign synthesis [10-15], we report herein, the synthesis of 1,4-diethyl-2,6-dioxo-1,2,5,6-tetrahydropyridine-3-carbonitrile, $\mathbf{8}$, as a good precursors to novel arylhydrazono-1,4-diethyl-2,6-dioxo-1,2,5,6-tetrahydropyridine-3-carbonitriles and their application as disperse dyes for the dyeing of polyester fabrics. Also the effect of dispersing agent on dye uptake and consequent dyeing properties are described.

\section{Experimental}

\subsection{Instrumentation}

Melting points were recorded on a Gallenkamp apparatus. IR spectra were recorded using $\mathrm{KBr}$ pellets on a JASCO FTIR6300 FT-IR spectrophotometer. ${ }^{1} \mathrm{H}$ and ${ }^{13} \mathrm{C}$ NMR spectra were recorded on Bruker DPX $400 \mathrm{MHz}$ or AvanceII $600 \mathrm{MHz}$ superconducting NMR spectrometers with proton spectra measured at $400,600 \mathrm{MHz}$ and carbon spectra at 100 and $150 \mathrm{MHz}$, respectively. Mass spectra were measured on a high resolution GC/MS DFS-Thermo. Microanalyses were performed on Elemental-Vario Micro cube Analyzer. The crystal structure of compounds 11a and 11b were determined by Bruker AXS X8 Prospector Single Crystal X-Ray Diffractometer at Kuwait University. Compound $\mathbf{4}$ is prepared according to published literature [16]. The crystal was kept at $296 \mathrm{~K}$ during data collection. The structure was solved with the Program SHELXL97 Software package.

\subsection{1,4-Diethyl-2,6-dioxo-1,2,5,6-tetrahydropyridine-3- carbonitrile (8)}

A mixture of $N$-ethyl cyanoacetamide $(1.12 \mathrm{~g}, 10 \mathrm{mmol})$ and methyl propionylacetate $(1.30 \mathrm{~g}, 10 \mathrm{mmol})$ was refluxed for six hours. The solution was diluted with water and acidified with hydrochloric acid to give white crystals (Scheme 1). Color: White. Yield: $90 \%$. M.p.: $224-226^{\circ} \mathrm{C}$. FT-IR (KBr, $\left.v, \mathrm{~cm}^{-1}\right): 3438$ $(\mathrm{OH}), 2223(\mathrm{CN}), 1645$ (CO). ${ }^{1} \mathrm{H}$ NMR $\left(400 \mathrm{MHz}, \mathrm{DMSO}-d_{6}, \delta\right.$, ppm): $1.12\left(\mathrm{~m}, 6 \mathrm{H}, 2 \mathrm{CH}_{3}\right), 2.50\left(\mathrm{q}, 2 \mathrm{H}, \mathrm{CH}_{2}, J=8 \mathrm{~Hz}\right), 3.93(\mathrm{q}$, $2 \mathrm{H}, \mathrm{CH}_{2}-\mathrm{N}, J=6.8 \mathrm{~Hz}$ ), 5.34 (br, $1 \mathrm{H}, \mathrm{CH}$-pyridone), $5.64(\mathrm{~s}, 1 \mathrm{H}$, $\mathrm{OH}, \mathrm{D}_{2} \mathrm{O}$ exchangeable). 

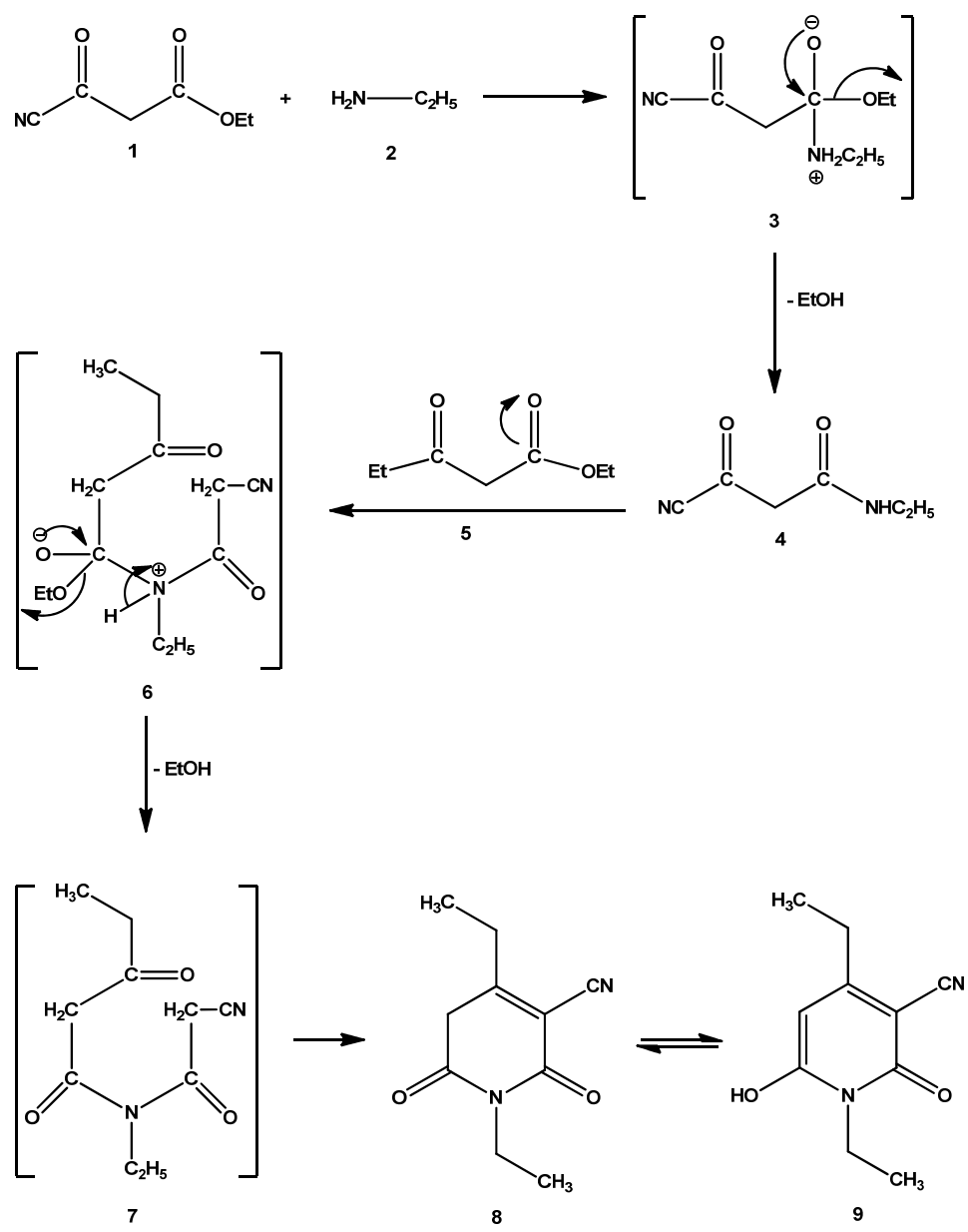

Scheme 1

${ }^{13} \mathrm{C}$ NMR (100 MHz, DMSO- $\left.d_{6}, \delta, \mathrm{ppm}\right): 13.0\left(\mathrm{CH}_{3}\right), 13.3$ $\left(\mathrm{CH}_{3}\right), 27.3\left(\mathrm{CH}_{2}\right), 35.8\left(\mathrm{CH}_{2}\right), 87.4,90.6,117.3,160.5,160.6$, 163.4. MS (m/z, (\%)): $192\left(\mathrm{M}^{+}, 93\right)$. Anal. calcd. for $\mathrm{C}_{10} \mathrm{H}_{12} \mathrm{~N}_{2} \mathrm{O}_{2}$ : C, 62.49; H, 6.29; N, 14.57. Found: C, 62.66; H, 6.98; N, 14.66\%.

\subsection{General procedure for the synthesis of azo disperse dyes (11a-d)}

A cold solution of aryldiazonium salt $(10 \mathrm{mmol})$, (prepared by adding a solution of sodium nitrite $\left(1.00 \mathrm{~g}\right.$ in $\left.10 \mathrm{~mL} \mathrm{H}_{2} \mathrm{O}\right)$ to a cold solution of arylamine hydrochloride $(10 \mathrm{mmol})$ with stirring as described earlier) [10]. The resulting solution of the aryldiazonium chloride was then added to a cold solution of compound $8(10 \mathrm{mmol})$ in ethanol $(20 \mathrm{~mL})$ containing sodium acetate $(2.00 \mathrm{~g})$. The mixture was stirred at room temperature for one $\mathrm{h}$ and the solid product so formed was collected by filtration and recrystallized from ethanol to give compounds 11a-d (Scheme 2).

1,4-Diethyl-2,6-dioxo-5-(phenylhydrazono)-1,2,5,6-tetrahydropyridine-3-carbonitrile (11a): Color: Yellow. Yield: 64\%. M.p.: 209-211 ${ }^{\circ} \mathrm{C}$. (Lit. [17] M.p.: 207-209 $\left.{ }^{\circ} \mathrm{C}\right)$. FT-IR (KBr, v, cm1): $3436(\mathrm{NH}), 2221(\mathrm{CN}), 1671,1631$ (CO). ${ }^{1} \mathrm{H}$ NMR ( $400 \mathrm{MHz}$, DMSO- $\left.d_{6}, \delta, \mathrm{ppm}\right): 1.14\left(\mathrm{t}, 3 \mathrm{H}, \mathrm{CH}_{3}, J=7.2 \mathrm{~Hz}\right), 1.27\left(\mathrm{t}, 3 \mathrm{H}, \mathrm{CH}_{3}, J\right.$ $=7.6 \mathrm{~Hz}), 2.93\left(\mathrm{q}, 2 \mathrm{H}, \mathrm{CH}_{2}, J=7.6 \mathrm{~Hz}\right), 3.88\left(\mathrm{q}, 2 \mathrm{H}, \mathrm{CH}_{2}, J=7.2\right.$ $\mathrm{Hz}), 7.31(\mathrm{t}, 1 \mathrm{H}, J=7.2 \mathrm{~Hz}$, phenyl- $\mathrm{H}), 7.51(\mathrm{t}, 2 \mathrm{H}, J=8.0 \mathrm{~Hz}$, phenyl-H), $7.70(\mathrm{~d}, 2 \mathrm{H}, J=8.0 \mathrm{~Hz}$, phenyl-H), $14.64(\mathrm{~s}, 1 \mathrm{H}, \mathrm{NH}$, $\mathrm{D}_{2} \mathrm{O}$ exchangeable). MS (m/z, (\%)): $296\left(\mathrm{M}^{+}, 100\right)$. Anal. calcd. for $\mathrm{C}_{16} \mathrm{H}_{16} \mathrm{~N}_{4} \mathrm{O}_{2}$ : C, 64.85; $\mathrm{H}, 5.44 ; \mathrm{N}, 18.91$. Found: $\mathrm{C}, 64.86 ; \mathrm{H}$, $5.95 ; \mathrm{N}, 18.92 \%$.

1,4-diethyl-2,6-dioxo-5-(2-p-tolylhydrazono)-1,2,5,6-tetrahydropyridine-3-carbonitrile (11b): Color: Dark orange. Yield: 65\%. M.p.: $173-175{ }^{\circ}$ C. FT-IR (KBr, $\left.v, \mathrm{~cm}^{-1}\right): 3440(\mathrm{NH}), 2224$ (CN), 1673, 1628 (CO). ${ }^{1} \mathrm{H}$ NMR $\left(400 \mathrm{MHz}, \mathrm{DMSO}-d_{6}, \delta, \mathrm{ppm}\right)$ $1.14\left(\mathrm{t}, 3 \mathrm{H}, J=7.2 \mathrm{~Hz}, \mathrm{CH}_{3}\right), 1.25\left(\mathrm{t}, 3 \mathrm{H}, J=7.6 \mathrm{~Hz}, \mathrm{CH}_{3}\right), 2.32(\mathrm{~s}$, $\left.3 \mathrm{H}, \mathrm{CH}_{3}\right), 2.89$ (q, $\left.2 \mathrm{H}, J=7.6 \mathrm{~Hz}, \mathrm{CH}_{2}\right), 3.86(\mathrm{q}, 2 \mathrm{H}, J=7.2 \mathrm{~Hz}$, $\mathrm{CH}_{2}$ ), $7.56(\mathrm{~d}, 2 \mathrm{H}, J=8.4 \mathrm{~Hz}, p$-tolyl-H), $7.70(\mathrm{~d}, 2 \mathrm{H}, J=8.4 \mathrm{~Hz}, p$ tolyl-H), 14.70 (s, $1 \mathrm{H}, \mathrm{NH}, \mathrm{D}_{2} \mathrm{O}$ exchangeable). $\mathrm{MS}(\mathrm{m} / \mathrm{z},(\%))$ : $310\left(\mathrm{M}^{+}, 84\right)$. Anal. calcd. for $\mathrm{C}_{17} \mathrm{H}_{18} \mathrm{~N}_{4} \mathrm{O}_{2}$ : $\mathrm{C}, 65.79 ; \mathrm{H}, 5.85 ; \mathrm{N}$, 18.05. Found: C, $65.67 ; \mathrm{H}, 5.98 ; \mathrm{N}, 18.97 \%$.

1,4-Diethyl-5-[(4-methoxyphenyl)-hydrazono]-2,6-dioxo-1,2, 5,6-tetrahydropyridine-3-carbonitrile (11c): Color: Orange. Yield: $72 \%$. M.p.: $228{ }^{\circ} \mathrm{C}$. (Lit. [17] M.p.: 226-228 ${ }^{\circ} \mathrm{C}$ ). FT-IR (KBr, $\left.v, \mathrm{~cm}^{-1}\right): 3436(\mathrm{NH}), 2224(\mathrm{CN}), 1675,1624$ (CO). ${ }^{1} \mathrm{H}$ NMR ( $\left.400 \mathrm{MHz}, \mathrm{DMSO}-d_{6}, \delta, \mathrm{ppm}\right): 1.13\left(\mathrm{t}, 3 \mathrm{H}, J=6.4 \mathrm{~Hz}, \mathrm{CH}_{3}\right), 1.24$ $\left(\mathrm{t}, 3 \mathrm{H}, J=7.2 \mathrm{~Hz}, \mathrm{CH}_{3}\right), 2.92\left(\mathrm{q}, 2 \mathrm{H}, J=8.4 \mathrm{~Hz}, \mathrm{CH}_{2}\right), 3.81(\mathrm{~s}, 3 \mathrm{H}$, $\left.\mathrm{OCH}_{3}\right), 3.88\left(\mathrm{q}, 2 \mathrm{H}, J=6.4 \mathrm{~Hz}, \mathrm{CH}_{2}\right), 7.07(\mathrm{~d}, 2 \mathrm{H}, J=8.4 \mathrm{~Hz}$, arom$\mathrm{H}), 7.68\left(\mathrm{~d}, 2 \mathrm{H}, J=8.4 \mathrm{~Hz}\right.$, arom-H), $14.85\left(\mathrm{~s}, 1 \mathrm{H}, \mathrm{NH}, \mathrm{D}_{2} \mathrm{O}\right.$ exchangeable). MS $(\mathrm{m} / \mathrm{z},(\%)): 326\left(\mathrm{M}^{+}, 100\right)$. Anal. calcd. for $\mathrm{C}_{17} \mathrm{H}_{18} \mathrm{~N}_{4} \mathrm{O}_{3}$ : C, 62.57; H, 5.56; N, 17.17. Found: C, 62.51; H, 5.91; $\mathrm{N}, 17.14 \%$.

5-(2-(4-chlorophenyl)hydrazono)-1,4-diethyl-2,6-dioxo-1,2, 5,6-tetrahydropyridine-3-carbonitrile (11d): Color: Dark yellow. Yield: $82 \%$. M.p.: $215-217^{\circ} \mathrm{C}$. FT-IR (KBr, v, cm-1): 3449 (NH), 2223 (CN), 1674, 1632 (CO). 

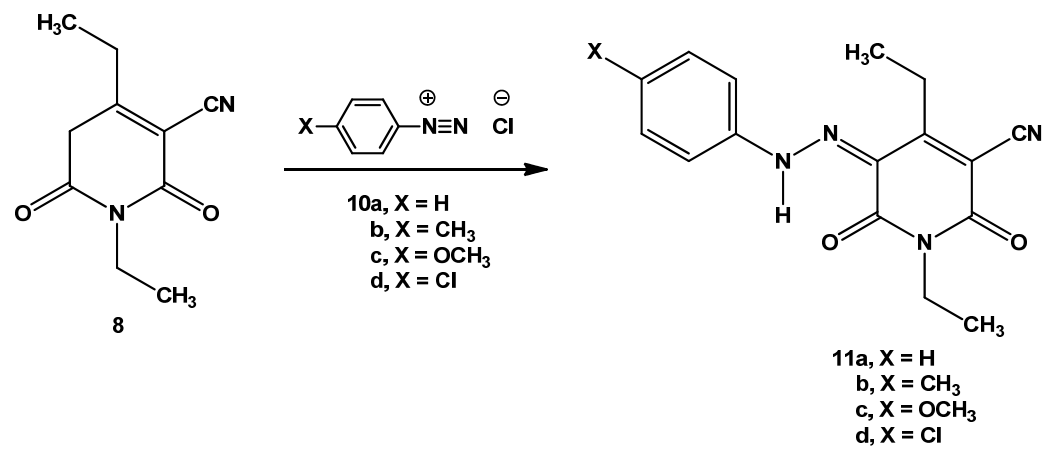

Scheme 2

${ }^{1} \mathrm{H}$ NMR (400 MHz, DMSO- $\left.d_{6}, \delta, \mathrm{ppm}\right): 1.14(\mathrm{t}, 3 \mathrm{H}, J=6.8 \mathrm{~Hz}$, $\left.\mathrm{CH}_{3}\right), 1.26\left(\mathrm{t}, 3 \mathrm{H}, J=7.6 \mathrm{~Hz}, \mathrm{CH}_{3}\right), 2.91\left(\mathrm{q}, 2 \mathrm{H}, J=7.6 \mathrm{~Hz}, \mathrm{CH}_{2}\right)$, $3.87\left(\mathrm{q}, 2 \mathrm{H}, J=6.8 \mathrm{~Hz}, \mathrm{CH}_{2}\right.$ ), $7.54(\mathrm{~d}, 2 \mathrm{H}, J=9.2 \mathrm{~Hz}$, arom- $\mathrm{H}$ ), $7.72\left(\mathrm{~d}, 2 \mathrm{H}, J=8.8 \mathrm{~Hz}\right.$, arom-H), $14.55\left(\mathrm{~s}, 1 \mathrm{H}, \mathrm{NH}, \mathrm{D}_{2} \mathrm{O}\right.$ exchangeable). ${ }^{13} \mathrm{C}$ NMR (100 MHz, DMSO- $\left.d_{6}, \delta, \mathrm{ppm}\right): 12.6$ $\left(\mathrm{CH}_{3}\right), 14.0\left(\mathrm{CH}_{3}\right), 23.6\left(\mathrm{CH}_{2}\right), 34.4\left(\mathrm{CH}_{2}\right), 99.8,114.7,119.0$, $122.1,129.7,130.8,140.3,160.0,160.3,163.9$. MS (m/z, (\%)): $330\left(\mathrm{M}^{+}, 100\right)$. Anal. calcd. for $\mathrm{C}_{16} \mathrm{H}_{15} \mathrm{ClN}_{4} \mathrm{O}_{2}: \mathrm{C}, 58.10 ; \mathrm{H}, 4.57$; N, 16.94. Found: C, 57.63; H, 5.00; N, $16.83 \%$.

\subsection{High temperature dyeing method (HT)}

\subsubsection{Materials}

Polyester 100\% (150 $130 \mathrm{~g} / \mathrm{m}^{2}, 70 / 2$ denier) was used. The fabric was treated before dyeing with a solution containing nonionic detergent (Hostapal CV, Clariant-Egypt, $5 \mathrm{~g} / \mathrm{L}$ ) and sodium carbonate $(2 \mathrm{~g} / \mathrm{L})$ in a ratio of $50: 1$ at $60^{\circ} \mathrm{C}$ for $30 \mathrm{~min}$, thoroughly washed with water, and air dried at room temperature.

\subsubsection{Dyeing}

A dispersion of the dye was produced by dissolving the appropriate amount of dye ( $5 \%$ shade) in $2 \mathrm{~mL}$ DMF and then added drop wise with stirring to the dye bath (liquor ration 50:1) containing sodium lignin sulfonate as dispersing agent. The dispersing agent: dye ratio ranged from 0:1 to $4: 1 \%$ (Table 1 ). The $\mathrm{pH}$ of the dyebath was adjusted to 4.5 using aqueous acetic acid and the wetted-out polyester fabrics were added. Dyeing was performed by raising the dyebath temperature to $130{ }^{\circ} \mathrm{C}$ under pressure in a dyeing machine at a rate of 15 ${ }^{\circ} \mathrm{C} / \mathrm{min}$, holding at this temperature for $60 \mathrm{~min}$ and cooling to $50{ }^{\circ} \mathrm{C}$. After dyeing, the fabrics were thoroughly washed and subjected to surface reduction clearing [ $(2 \mathrm{~g} \mathrm{NaOH}+2 \mathrm{~g}$ sodium hydrosulphite)/L]. The samples were heated in this solution for $10 \mathrm{~min}$ at $60^{\circ} \mathrm{C}$ and then thoroughly washed and air-dried.

\subsection{Color measurements and analyses}

\subsubsection{Color measurements of the dyed fabrics}

The color yields of the dyed samples were determined by using the light reflectance technique performed on a PerkinElmer (Lambda 3B) UV/VIS Spectrophotometer. The color strengths, expressed as K/S values, were determined by applying the Kubelka-Mink Equation 1.

$K / S=\left[(1-R)^{2} / 2 R\right]-\left[\left(1-R_{0}\right)^{2} / 2 R_{0}\right]$

where $R$ = decimal fraction of the reflectance of the dyed fabric, $R_{o}=$ decimal fraction of the reflectance of the undyed fabric, $K=$ absorption coefficient, and $S=$ scattering coefficient.

\subsubsection{Color fastness tests}

\subsubsection{Fastness to washing.}

After washing using $5 \mathrm{~g} / \mathrm{L}$ of the nonionic detergent Hostapal CV and $2 \mathrm{~g} / \mathrm{L}$ of sodium carbonate at $80^{\circ} \mathrm{C}$ for $15 \mathrm{~min}$, the dyed fabrics were tested by using ISO-standard methods [18]. A specimen of dyed polyester fabric was stitched between two pieces of undyed cotton and wool fabrics, all of equal length, and then washed at $95{ }^{\circ} \mathrm{C}$ for $30 \mathrm{~min}$. The staining on the undyed adjacent fabrics was assessed with gray scale: $1-$ poor, 2-fair, 3-moderate, 4-good, 5-excellent.

\subsubsection{Fastness to perspiration}

The samples were prepared by stitching a piece of dyed polyester fabric between two pieces of cotton and wool fabrics, all of equal length, and then immersed in the acid or alkaline solution for $30 \mathrm{~min}$. The staining on the undyed adjacent fabrics was assessed with gray scale: 1 - poor, 2-fair, 3-moderate, 4-good, 5-excellent. The acid solution $(\mathrm{pH}=4.5)$ contains sodium chloride $(10 \mathrm{~g} / \mathrm{L})$, sodium dihydrogen orthophosphate $(1 \mathrm{~g} / \mathrm{L})$ and histidine monohydrochloride $(0.25 \mathrm{~g} / \mathrm{L})$. The alkaline solution $(\mathrm{pH}=8.7)$ contains sodium chloride $(10 \mathrm{~g} / \mathrm{L})$, disodium orthophosphate $(1 \mathrm{~g} / \mathrm{L})$ and histidine monohydro chloride $(0.25 \mathrm{~g} / \mathrm{L})$.

\section{Results and discussion}

In order to study the effect of dispersing agent on dye uptake and consequent dyeing properties, several disperse dyes based on pyridones moiety are synthesized. Our initial strategy aimed to synthesize compound $\mathbf{8}$ and convert it to the corresponding arylhydrazono-1,4-diethyl-2,6-dioxo-1,2,5,6tetrahydropyridine-3-carbonitrile 11a-d, which are anticipated to be excellent new disperse dyes for the dyeing of polyester fabrics employing high temperature dyeing method. Compound $\mathbf{8}$ is synthesized by reacting ethyl cyanoacetate, with ethyl amine to produce the amide derivative 4 , which reacts with methyl propionylacetate to afford 1,4-diethyl-2,6-dioxo-1,2,5,6tetrahydropyridine-3-carbonitrile, $\mathbf{8}$. Compound $\mathbf{8}$ may be exist in another tautmeric form $\mathbf{9}$ and in solution there is a very fast equilibration between them $[19,20]$. The formation of compound $\mathbf{8}$ is assumed to proceed via intermediacy of compounds 3, $\mathbf{6}$ and $\mathbf{7}$ (Scheme 1).

Coupling of compound $\mathbf{8}$ with aromatic diazonium salts afforded the corresponding disperse dyes 11a-d. Structural assignments of these dyes were confirmed unambiguously by the X-ray crystallographic data provided below (Scheme 2), (Figures 1 and 2). 
Table 1. Shade and optical measurements of the azo disperse dyes on the polyester fabrics.

\begin{tabular}{|c|c|c|c|c|c|c|c|c|}
\hline Dye No & Color shade on polyester & Dispersing agent ratio \% & $L^{*}$ & $a^{*}$ & $b^{*}$ & $C^{*}$ & $h^{*}$ & $K / S$ \\
\hline \multirow[t]{5}{*}{$11 \mathrm{a}$} & Yellow & 0 & 82.53 & 6.27 & 108.95 & 82.53 & 109.13 & 30.03 \\
\hline & & 1 & 82.12 & 6.25 & 108.03 & 82.12 & 108.21 & 30.21 \\
\hline & & 2 & 81.83 & 6.55 & 107.88 & 81.83 & 108.08 & 30.58 \\
\hline & & 3 & 81.63 & 6.62 & 107.56 & 81.63 & 107.77 & 30.74 \\
\hline & & 4 & 80.98 & 7.10 & 106.95 & 80.98 & 107.19 & 31.15 \\
\hline \multirow[t]{5}{*}{$11 b$} & Dark orange & 0 & 48.05 & 50.14 & 59.23 & 48.05 & 77.60 & 30.42 \\
\hline & & 1 & 47.06 & 50.56 & 58.10 & 47.06 & 77.02 & 31.45 \\
\hline & & 2 & 48.20 & 50.37 & 60.63 & 48.20 & 78.83 & 32.90 \\
\hline & & 3 & 48.59 & 50.47 & 61.27 & 48.59 & 79.38 & 33.23 \\
\hline & & 4 & 47.91 & 50.96 & 60.40 & 47.91 & 79.03 & 33.52 \\
\hline \multirow[t]{5}{*}{$\overline{11 c}$} & Orange & 0 & 63.05 & 40.86 & 84.52 & 63.05 & 93.88 & 30.76 \\
\hline & & 1 & 64.79 & 42.20 & 87.89 & 64.79 & 97.49 & 31.21 \\
\hline & & 2 & 64.17 & 42.19 & 86.95 & 64.17 & 96.65 & 31.97 \\
\hline & & 3 & 63.98 & 42.38 & 87.00 & 63.98 & 96.78 & 32.15 \\
\hline & & 4 & 64.02 & 42.50 & 87.43 & 64.02 & 97.21 & 32.95 \\
\hline \multirow[t]{5}{*}{$11 \mathrm{~d}$} & Dark yellow & 0 & 81.06 & 10.96 & 109.39 & 81.06 & 109.93 & 30.09 \\
\hline & & 1 & 80.28 & 11.42 & 108.51 & 80.28 & 109.11 & 30.22 \\
\hline & & 2 & 79.91 & 11.63 & 108.17 & 79.91 & 108.79 & 31.01 \\
\hline & & 3 & 79.85 & 11.55 & 108.16 & 79.85 & 108.77 & 31.23 \\
\hline & & 4 & 79.69 & 11.72 & 108.05 & 79.69 & 108.69 & 31.58 \\
\hline
\end{tabular}

Table 2. Fastness properties of azo disperse dyes on polyester fabrics without using dispersing agent.

\begin{tabular}{|c|c|c|c|c|c|c|c|c|c|}
\hline \multirow[t]{3}{*}{ Dye No } & \multirow{2}{*}{\multicolumn{3}{|c|}{ Wash fastness }} & \multicolumn{6}{|c|}{ Perspiration fastness } \\
\hline & & & & \multicolumn{3}{|c|}{ Alkaline } & \multicolumn{3}{|c|}{ Acidic } \\
\hline & Alt & SC & SW & Alt & SC & SW & Alt & SC & SW \\
\hline$\overline{11 a}$ & 5 & 5 & 4 & 5 & 5 & 5 & 5 & 5 & 5 \\
\hline $11 b$ & 5 & $4-5$ & 4 & 5 & 5 & 5 & 5 & 5 & 5 \\
\hline $11 c$ & 5 & 5 & 5 & 5 & 5 & 5 & 5 & 5 & 5 \\
\hline $11 \mathrm{~d}$ & 5 & 5 & $4-5$ & 5 & 5 & 5 & 5 & 5 & 5 \\
\hline
\end{tabular}

Alt = alteration; SC = staining on cotton; SW = staining on wool.

Table 3. Fastness properties of azo disperse dyes on polyester fabrics by using dispersing agent 4\%.

\begin{tabular}{|c|c|c|c|c|c|c|c|c|c|}
\hline \multirow[t]{3}{*}{ Dye No } & \multirow{2}{*}{\multicolumn{3}{|c|}{ Wash fastness }} & \multicolumn{6}{|c|}{ Perspiration fastness } \\
\hline & & & & \multicolumn{3}{|c|}{ Alkaline } & \multicolumn{3}{|c|}{ Acidic } \\
\hline & Alt & SC & SW & Alt & SC & SW & Alt & SC & SW \\
\hline$\overline{11 a}$ & 5 & $4-5$ & $3-4$ & 5 & 5 & 5 & 5 & 5 & 5 \\
\hline $11 \mathrm{~b}$ & $4-5$ & $4-5$ & 3 & 5 & 5 & 5 & $4-5$ & $4-5$ & $4-5$ \\
\hline $11 \mathrm{c}$ & 5 & 5 & $4-5$ & 5 & 5 & 5 & 5 & 5 & 5 \\
\hline $11 \mathrm{~d}$ & $4-5$ & 5 & 4 & 5 & 5 & 5 & 5 & 5 & 5 \\
\hline
\end{tabular}

Alt = alteration; $\mathrm{SC}=$ staining on cotton; $\mathrm{SW}=$ staining on wool.

Disperse dyes 11a-d were applied to polyester fabrics at 5\% (dye shade), using high temperature dyeing method (HT) at $130{ }^{\circ} \mathrm{C}$. Dark orange, dark yellow, orange and yellow color shades were obtained. The dyeing properties on the polyester fabrics were evaluated in terms of their fastness properties (e.g., fastness to washing and perspiration). The color of dyeing on polyester fabrics is expressed in terms of CIELab color space values (Table 1), and the following CIELAB coordinates were measured: lightness $\left(L^{*}\right)$; chroma $\left(C^{*}\right)$; hue angle $(h)$ from 0 to $360^{\circ} ; a^{*}$, whose value represents the degree of redness (positive) and greenness (negative); and $b^{*}$, whose value represents the degree of yellowness (positive) and blueness (negative). For dyeing polyester fibres, in practical terms only disperse dyes are suitable. Through their hydrophobic properties, these dyes are capable of penetrating into the similarly hydrophobic polyester fibre. This class of dyes has extremely poor solubility in water, for this reason, dispersing agent is added to the dyebath to maintain dispersion stability, especially in the case of high temperature dyeing [21]. Table 1 , shows the relationship between $K / S$ as a parameter for dye uptake and the concentrations of the dispersing agent used from 0 (no dispersing agent used) to $4 \%$ present in a dyebath, the $K / S$ increase with increasing amount of dispersing agent applied. These results in this study support the findings of the other researchers who showed the linear relationship between dye uptake and the concentrations of the dispersing agent, dispersing agent increase the aqueous solubility of disperse dyes and increase the affinity of the disperse dyes for the aqueous phase, and effect both the rate and extent of uptake of disperse dyes on hydrophobic fibers [22,23].

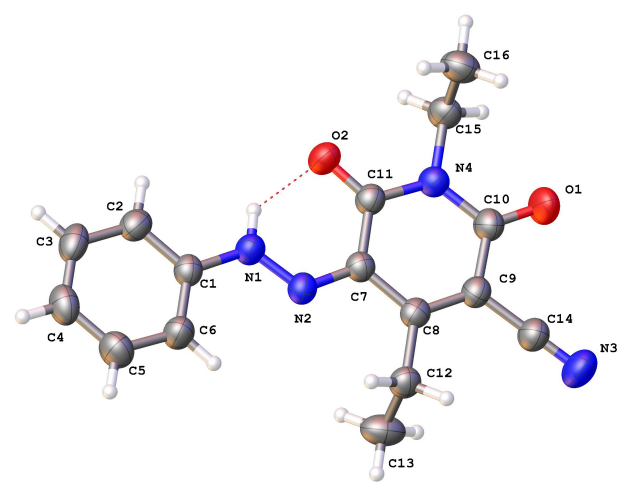

Figure 1. Molecular structure of compound 11a in the crystal showing the atom numbering scheme. The thermal ellipsoids are drawn at the $50 \%$ probability level.

In general, the positive values of $b^{*}$ (yellow-blue axis) indicated that the color hues of the all disperse dyes on the polyester fabric shifted to the yellowish directions. The physical data for the dyed fabrics with dispersing agent, given in Table 2, shows that the disperse dyeing displayed very good fastness levels to washing and excellent fastness levels to perspiration. While, the dyed fabrics without dispersing agent given in Table 3 have good fastness levels to washing and very good fastness levels to perspiration that means dyeing properties could be improved by adding dispersing agent. 
Comparison between conventional and microwave dyeing, biological activities, and evaluation of dyeing behaviour for these arylhydrazopyridones disperse dyes are under investigation.

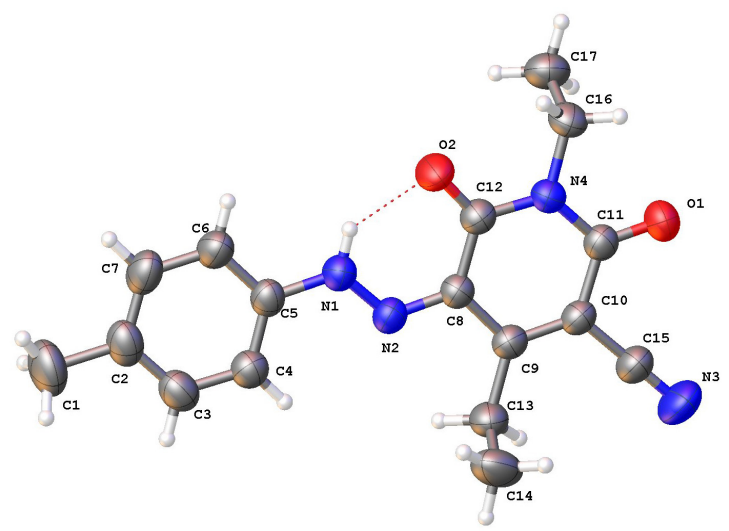

Figure 2. Molecular structure of compound 11b in the crystal showing the atom numbering scheme. The thermal ellipsoids are drawn at the $50 \%$ probability level.

\section{Conclusion}

The dyes produced in this study were applied to polyester fabrics by using high temperature dyeing method at $130^{\circ} \mathrm{C}$. The dyed fabrics with dispersing agent, which displayed yellow to dark orange on polyester fabrics, have very good fastness levels to washing and excellent fastness levels to perspiration, while the dyed fabrics without dispersing agent has good fastness levels to washing and very good fastness levels to perspiration.

\section{Acknowledgements}

The facilities of GF-S provided by Kuwait University, supported by research grants (GS03/08), (GS01/01), (GS01/03) and (GS01/05) are highly appreciated.

\section{Supplementary material}

CCDC-925725 and 925785 of compound 11a and 11b contains the supplementary crystallographic data for this paper. These data can be obtained free of charge via www.ccdc.cam.ac.uk/data request/cif or by e-mailing data request@ccdc.cam.ac.uk, or by contacting The Cambridge Crystallographic Data Centre, 12 Union Road, Cambridge CB2 1EZ, UK; fax: +44(0)1223-336033.

\section{References}

[1]. Heimann, S. Rev. Prog. Color. 1981, 11,1-8.

[2]. Baumgarte, U. Rev. Prog. Color. 1974, 5, 12-16.

[3]. McDowell, W. Weingarten, R. J. Soc. Dyers. Colour 1969, 85, 589-597.

[4]. McGregor, R.; Peters, R. H. J. Soc. Dyers. Colour 1965, 81, 393-400

[5]. Odvkrka, J.; Schejbalova, H. J. Soc. Dyers. Colour 1994, 1, 30-34.

[6]. Al-Zaydi, K. M.; Borik, R. M.; Elnagdi, M. H. Ultrason. Sonochem. 2009, 16, 660-668.

[7]. Ashkar, S. M.; El-Apasery, M. A.; Touma, M. M.; Elnagdi, M. H. Molecules 2012, 17, 8822-8831.

[8]. Chien, C. C.; Wang, I. J. Dyes Pigments 1991, 15, 69-82.

[9]. Ertan, N.; Gurkan, P. Dyes Pigments 1997, 33, 137-147.

[10]. Al-Etaibi, A. M.; El-Apasery, M. A.; Huda, H. M.; Al-Awadi, N. A. Molecules 2012, 17, 4266-4280.

[11]. Al-Etaibi, A. M.; Al-Awadi, N. A.; El-Apasery, M. A.; Ibrahim, M. R. Molecules 2011, 16, 5182-5193.

[12]. Al-Etaibi, A. M.; Al-Awadi, N. A.; El-Apasery, M. A.; Ibrahim, M. R. Molecules 2012, 17, 13891-13909.

[13]. EI-Apasery, M. A.; Al-Mousawi, S. M.; Mahmoud, H.; Elnagdi, M. H. Int. Res. J. Pure. Appl. Chem. 2011, 1, 69-83.

[14]. El-Apasery, M. A. J. Appl. Polym. Sci. 2008, 109, 695-699.

[15]. El-Apasery, M. A. Pol. J. Appl. Chem 2006, 50, 75-81.
[16]. Aleksandar, D.; Nedeljkovic, M. J.; Mijin, D. Z.; Ilic, N.; Petrovic, S. D. Chem. Ind. Chem. Eng. Q. 2011, 17, 307-314.

[17]. Al-Mousawi, S. M.; Abdelhamidb, I. A.; Moustafa, S. M. Arkivoc 2007, 1 213-221.

[18]. Chrysler. L. P. Methods of Test for Color Fastness of Textiles and Leather, $7^{\text {th }}$ ed.; Bradford: London 1990, pp. 89-94.

[19]. Elguero, J.; Marzin, C.; Katritzky, A. R.; Linda, P. The Tautomerism of Heterocyles in Adv Heterocycl Chem, Academic Press, 1976, pp. 106109.

[20]. Balalaie, S.; Kowsari, E.; Hashtroudi, M. S. Monats. Chem. 2003, 134, 453-456.

[21]. Koh, J. Dyeing with Disperse Dyes, Textile Dyeing. Prof. Peter Hauser (Ed.), InTech, 2011, pp. 195-220. DOI: 10.5772/20458

[22]. Khatibzadeh, M.; Mohseni, M.; Moradian, S. J. Fiber Bioeng. Inform 2012, 5, 455-464.

[23]. Park, K. H.; Casetta, M.; Koncar, V. Color. Technol. 2002, 118, 319-324. 